\title{
Voices of HIV-infected children
}

Letter to the Editor

Carta ao Editor

Beuy Joob ${ }^{1}$

Viroj Wiwanitkit ${ }^{2}$
Correspondence address:

Beuy Joob

Sanitation 1 Medical Academic Center Bangkok, Thailand, 10130.

E-mail: beuyjoob@hotmail.com

Received: January 05, 2018

Accepted: February 11, 2018

\section{Vozes de crianças infectadas pelo HIV}

\section{LETTER TO THE EDITORS}

Dear Editor, the publication on "Auditory-perceptual and acoustic analysis of voices of HIV-infected children" is very interesting ${ }^{(1)}$. Pereira et al. concluded that "HIV-infected children presented similar vocal quality to children without the illness, both for the perceptual-auditory and acoustic evaluation"(1). In fact, the vocal quality of children should not be different regardless of HIV infected status. Nevertheless, the HIV infected children with poor immune status are usually superimposed with opportunistic medical disorders which might affect the vocal quality. In HIV infected cases with severe immunodeficient status, there might be an abnormal laryngeal electromyography and poor vocal quality ${ }^{(2)}$. The CMV infection, which is a common opportunistic infection in HIV infected patients with late stages of disease, is a possible important cause of poor vocal quality ${ }^{(3)}$. In the present report by Pereira et al., if there is additional classification of immune status of the HIV infected children, there might be some difference in subgroup analysis.

Study conducted at Sanitation 1 Medical Academic Center - Bangkok, Thailand.

${ }^{1}$ Sanitation 1, Medical Academic Center - Bangkok, Thailand.

${ }^{2}$ Hainan Medical University - Haikou, China

Financial support: nothing to declare.

Conflict of interests: nothing to declare. 


\section{REFERENCES}

1. Pereira EC, Rodrigues CO, Silvério KCA, Madazio G, Behlau M. Auditoryperceptual and acoustic analysis of voices of HIV-infected children. CoDAS. 2017;29(6):e20170022. http://dx.doi.org/10.1590/2317-1782/201720170022. PMid:29236906.

2. Sims HS, Patel S, Barr A. Laryngeal electromyography findings in a patient with HIV, John Cunningham virus and bilateral true vocal fold motion impairment. J Natl Med Assoc. 2008;100(7):856-8. http://dx.doi. org/10.1016/S0027-9684(15)31381-X. PMid:18672564.
3. De la Blanchardiere A, Dore M, Salmon D, Sicard D. Left vocal cord paralysis in cytomegalovirus multifocal neuropathy in a patient with HIV infection. Presse Med. 1996;25(3):106-7. PMid:8746083.

\section{Author contributions}

BJ $50 \%$ (participated, in the condition of guiding, the idealization of the study, analysis, interpretation of data and writing of the article.); VW $50 \%$ (participated, in the condition of guiding, the idealization of the study, analysis, interpretation of data and writing of the article). 